
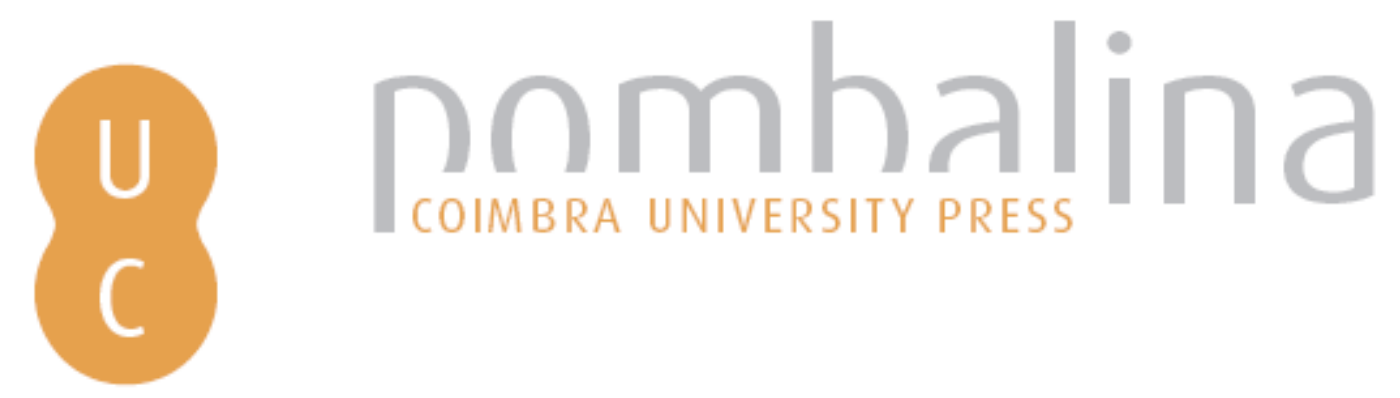

\title{
Comparação entre a função do receptor no domínio do tempo e da frequência para o cálculo de espessura crustal
}

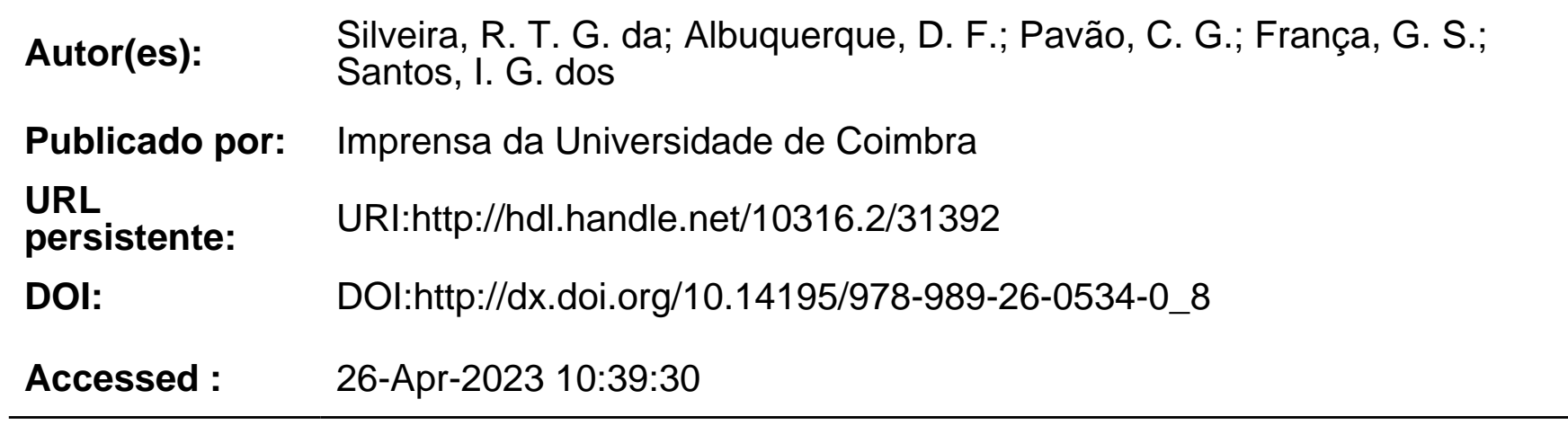

A navegação consulta e descarregamento dos títulos inseridos nas Bibliotecas Digitais UC Digitalis, UC Pombalina e UC Impactum, pressupõem a aceitação plena e sem reservas dos Termos e Condições de Uso destas Bibliotecas Digitais, disponíveis em https://digitalis.uc.pt/pt-pt/termos.

Conforme exposto nos referidos Termos e Condições de Uso, o descarregamento de títulos de acesso restrito requer uma licença válida de autorização devendo o utilizador aceder ao(s) documento(s) a partir de um endereço de IP da instituição detentora da supramencionada licença.

Ao utilizador é apenas permitido o descarregamento para uso pessoal, pelo que o emprego do(s) título(s) descarregado(s) para outro fim, designadamente comercial, carece de autorização do respetivo autor ou editor da obra.

Na medida em que todas as obras da UC Digitalis se encontram protegidas pelo Código do Direito de Autor e Direitos Conexos e demais legislação aplicável, toda a cópia, parcial ou total, deste documento, nos casos em que é legalmente admitida, deverá conter ou fazer-se acompanhar por este aviso.





8

\title{
COMPARAÇÁO ENTRE A FUNÇÁO DO RECEPTOR NO DOMÍNIO DO TEMPO E DA FREQUÊNCIA PARA O CÁLCULO DE ESPESSURA CRUSTAL
}

\author{
COMPARISON BETWEEN RECEIVER FUNCTIONS \\ IN TIME DOMAIN AND FREQUENCY DOMAIN \\ TO CALCULATE CRUSTAL THICKNESS
}

R. T. G. da Silveira ${ }^{1}$, D. F. Albuquerque ${ }^{1}$, C. G. Pavão', G. S. França ${ }^{1} \&$ I. G. dos Santos ${ }^{1}$

\begin{abstract}
Resumo - A Função do Receptor tem sido largamente utilizada para a determinação de espessura crustal e razão $\mathrm{Vp} / \mathrm{Vs}$. Neste trabalho foram utilizadas sete estaçóes pertencentes ao Observatório Sismológico da Universidade de Brasília (Brasil) para calcular a espessura crustal e a razão Vp/Vs: BRA7 (Brasília-DF), CAN3 (Palmeirópolis-GO), FOR1 (Fortaleza-CE), JAN7 (Itacarambi-MG), PDRB (Porto dos Gaúchos-MT), SFA1 (Catalão-GO), TUCA (Tucuruí-PA). A Função do Receptor foi aplicada nos domínios do tempo (LIGORRÍA \& AMMON, 1999) e da frequência (LANGSTON, 1979; OWENS, 1984; AMMON, 1991). Por meio destes métodos, foi estabelecido um comparativo entre os resultados obtidos por cada um.
\end{abstract}

Palavras-chave - Função do receptor; Espessura crustal; Razão Vp/Vs; Domínio do tempo; Domínio da frequência

Abstract - The Receiver Function has been widely used to determine the crustal thickness and the $V p / V s$ ratio. In this work seven stations belonging to Seismological Observatory of Brasilia University (Brazil) were used to calculate the crustal thickness and Vp/Vs ratio: BRA7 (Brasilia-DF), CAN3 (Palmeirópolis GO), FOR1 (Fortaleza-CE), JAN7 (Itacarambi-MG), PDRB (Porto dos Gaúchos-MT), SFA1 (Catalão-GO), TUCA (Tucurui-PA). The Receiver Function was applied in time domain (LIGORRIA \& AMMON, 1999) and in frequency

\footnotetext{
1 Observatório Sismológico, Instituto de Geociências, Universidade de Brasília; toscanisilveira@gmail. com; diogofarrapo@gmail.com
} 
domain (LANGSTON, 1979; OWENS, 1984; AMMON, 1991). Through these methods, we established a comparison between the results obtained by each one.

Keywords - Receiver function; Thickness of the crust; $V p / V s$ ratio; Time domain; Frequency domain

\section{1 - Introdução}

A Função do Receptor (FR) é uma técnica geofísica que utiliza registros telessísmicos para estudar as diversas estruturas que compóem a subsuperfície. Basicamente, esta técnica é utilizada para estimar a espessura da crosta e a razão $\mathrm{Vp} / \mathrm{Vs}$ logo abaixo de uma estação sismográfica.

O presente trabalho traz a estimativa das espessuras crustais e da razão $\mathrm{Vp} / \mathrm{Vs}$ para as estaçôes BRA7 (Brasília-DF), CAN3 (Palmeirópolis-GO), FOR1 (Fortaleza-CE), JAN7 (Itamcarambi-MG), PDRB (Porto dos Gaúchos-MT), SFA1 (Catalão-GO) e TUCA (Tucuruí-PA) (Fig. 1).

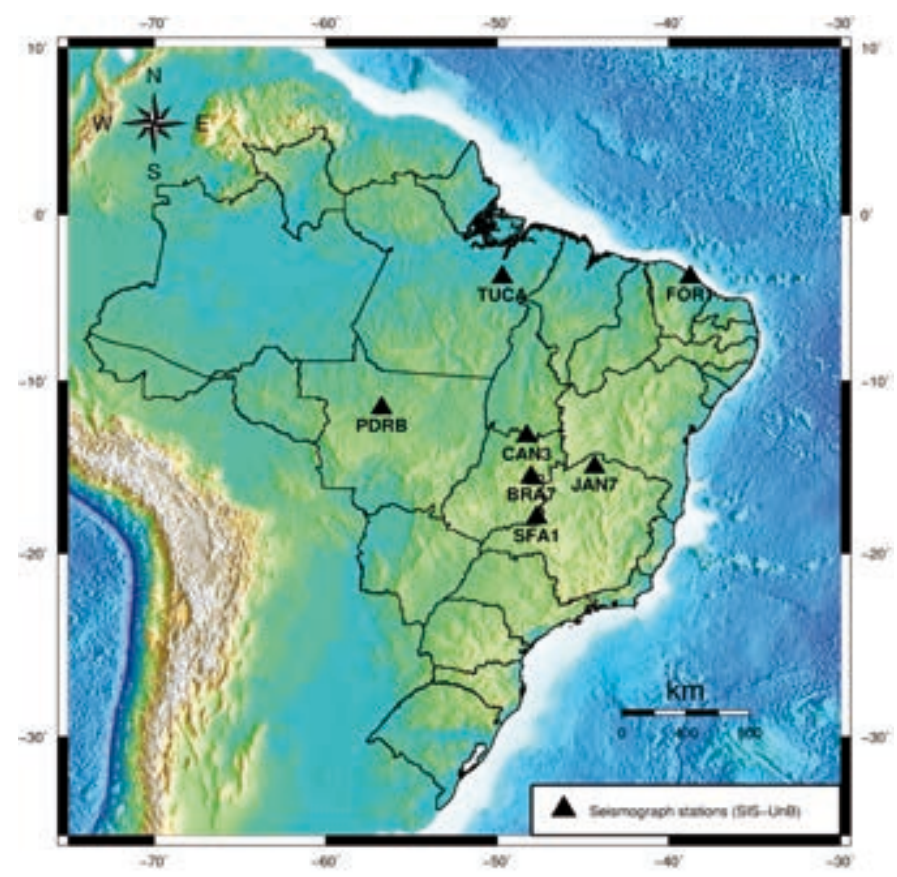

Fig. 1 - Localização das estaçôes sismográficas utilizadas no estudo.

Esses resultados foram obtidos por meio da Função do Receptor (FR) no domínio do tempo (LIGORRÍA \& AMMON, 1999) e da frequência, sendo o programa PWSS (Phase Weighted Slant Stacking, BIANCHI, 2008) utilizado para as estimativas de espessura crustal e razão Vp/Vs no domínio do tempo e o HK-Stacking (ZHU \& KANAMORI, 2000) para 
o domínio da frequência. Foram comparados com estudos prévios no domínio da frequência e, assim, foram considerados satisfatórios. $\mathrm{O}$ trabalho pretende contribuir para futuras discussóes geológicas, oferecendo mais informações de qualidade sobre a espessura crustal. Pretende-se também melhorar a acurácia dos resultados obtidos e, ainda, compreender e disseminar o uso da metodologia da Função do Receptor no domínio do tempo e da frequência.

\section{2 - Metodologia}

A Função do Receptor (FR) é composta por uma série temporal calculada nas três componentes de um sismograma. A FR se baseia no fenômeno da refração sísmica que ocorre quando a onda Primária (P) atinge a descontinuidade Mohorovičić (limite entre a crosta e o manto) e tem parte de sua energia convertida em onda $S$ (fase Ps) e em diversas reflexôes múltiplas (PpPms). Através da deconvolução no domínio da frequência ou do tempo e a rotação no sistema de eixos radial-tangencial, temos a Função do Receptor, que mostra um registro em que o maior pico será correspondente à onda $\mathrm{P}$ direta, enquanto os picos seguintes serão a fase Ps e as reflexóes múltiplas, respectivamente (Fig. 2).

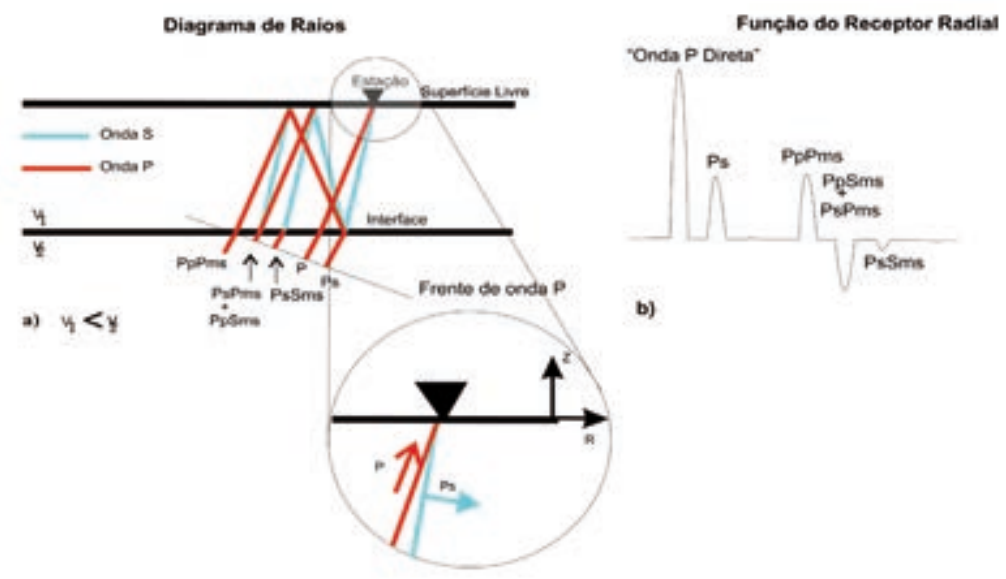

Fig. 2 - a) Diagrama de raios que ilustra a conversão da onda P para $S$ (fase Ps);

b) Registro radial, apresentando as fases P, Ps e múltiplas (FRANÇA, 2003).

Foram escolhidos telessismos com distâncias epicentrais variando de $30^{\circ}$ a $100^{\circ} \mathrm{e}$ magnitudes maiores ou iguais a 4,5 M $\mathrm{M}_{\mathrm{b}}$ (Fig. 3) (Para maiores informaçóes sobres esses sismos verificar a lista no link http://www.4shared.com/office/SJuCQQwx/file.html). A inspeção visual dos eventos foi realizada por meio do programa SAC (Seismic Analysis Code; GOLDSTEIN \& SNOKE, 2005). O programa PWSS (BIANCHI, 2008) foi utilizado para o processo de empilhamento no domínio do tempo, e o HK-Stacking (ZHU \& KANAMORI, 2000) para o domínio da frequência. Já a deconvolução no domínio do tempo foi executada pelo programa interdecon (AMMON, 1997) e no da frequência pelo pwaveqn (AMMON, 1991). 
Por meio dos programas Getlist e Getevts foi baixado e organizado um catálogo de eventos sísmicos comparando com os registros das estaçóes da rede IRIS (Incorporated Research Institutions for Seismology).

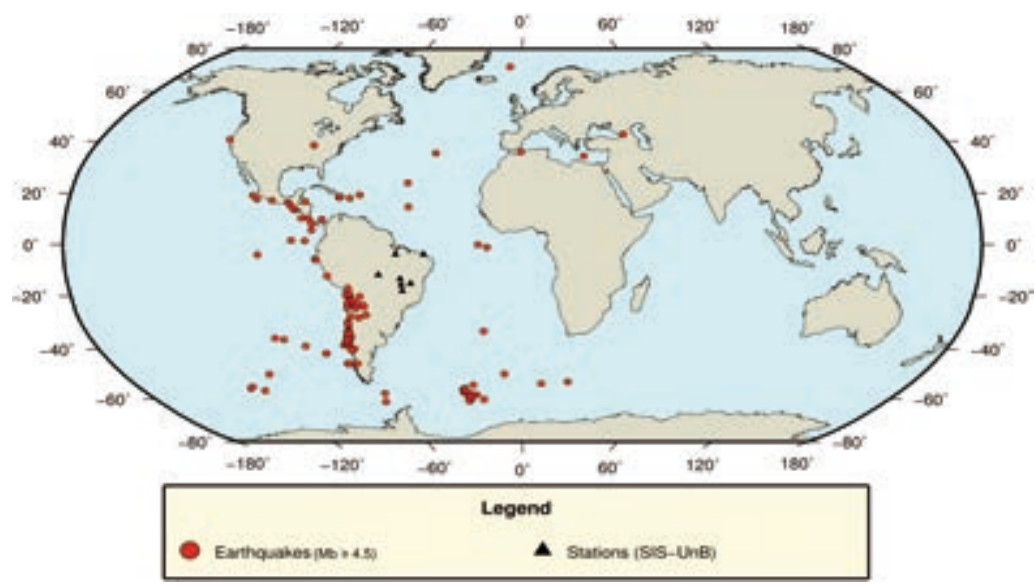

Fig. 3 - Localização dos epicentros dos telessismos e das estações sismográficas utilizadas no estudo.

Note a maior ocorrência de sismos oriundos do sudoeste sul americano (regiâo da Cordilheira dos Andes).

\section{3 - Resultados}

Os valores de espessura crustal $(\mathrm{H})$ e razão $\mathrm{Vp} / \mathrm{Vs}$ obtidos por meio de cada método estão listados na Tabela 1.

Tabela 1 - Valores de espessura crustal e razão $\mathrm{Vp} / \mathrm{Vs}$.

\begin{tabular}{cccccc}
\hline Estação & $\begin{array}{c}\mathrm{H}(\mathrm{Km}) \\
\text { Domínio do } \\
\text { tempo }\end{array}$ & $\begin{array}{c}\mathrm{H}(\mathrm{Km}) \\
\text { Domínio da } \\
\text { Frequência }\end{array}$ & $\mathrm{Vp}(\mathrm{Km} / \mathrm{s})$ & $\begin{array}{c}\mathrm{Vp} / \mathrm{Vs} \\
\text { Domínio do } \\
\text { tempo }\end{array}$ & $\begin{array}{c}\mathrm{Vp} / \mathrm{Vs}^{\mathrm{D}} \\
\text { Domínio da } \\
\text { frequência }\end{array}$ \\
\hline BRA7 & $42,64 \pm 0,74$ & $41,7 \pm 0,6$ & 6,4 & $1,68 \pm 0,02$ & $1,69 \pm 0,02$ \\
CAN3 & $39,31 \pm 2,26$ & $40,0 \pm 1,6$ & 6,4 & $1,64 \pm 0,07$ & $1,64 \pm 0,03$ \\
FOR1 & $34,23 \pm 1,50$ & $32,4 \pm 0,8$ & 6,4 & $1,69 \pm 0,06$ & $1,75 \pm 0,02$ \\
JAN7 & $39,83 \pm 0,00$ & $40,2 \pm 0,4$ & 6,4 & $1,73 \pm 0,00$ & $1,71 \pm 0,01$ \\
PDRB & $31,81 \pm 0,25$ & $37,5 \pm 2,2$ & 6,4 & $2,03 \pm 0,01$ & $1,80 \pm 0,12$ \\
SFA1 & $43,89 \pm 0,74$ & $37,2 \pm 2,4$ & 6,4 & $1,69 \pm 0,02$ & $1,69 \pm 0,06$ \\
TUCA & $37,22 \pm 0,50$ & $39,9 \pm 1,6$ & 6,4 & $1,81 \pm 0,02$ & $1,74 \pm 0,03$ \\
\hline
\end{tabular}


Em todos os resultados da Função do Receptor, as fases P e Ps são claramente identificáveis, tanto no domínio do tempo quanto da frequência. Um dos problemas encontrados foi a ambiguidade do resultado de espessura crustal causado pela concentraçáo de azimutes dos eventos detectados pela estação sismográfica CAN3 (AMMOM et al., 1990). A explicação para isso reside no fato de todos os eventos trazerem informação apenas de uma direção, não sendo corroborados por telessismos de outras direções. Infelizmente, a localização desta estação não permite que haja grande variação na direção azimutal.

As figuras abaixo mostram a Função do Receptor no domínio do tempo e no domínio da frequência para as estações BRA7 e FOR1. Note que a fase Ps está bem visível em cada registro selecionado (Figs. 4 e 5).
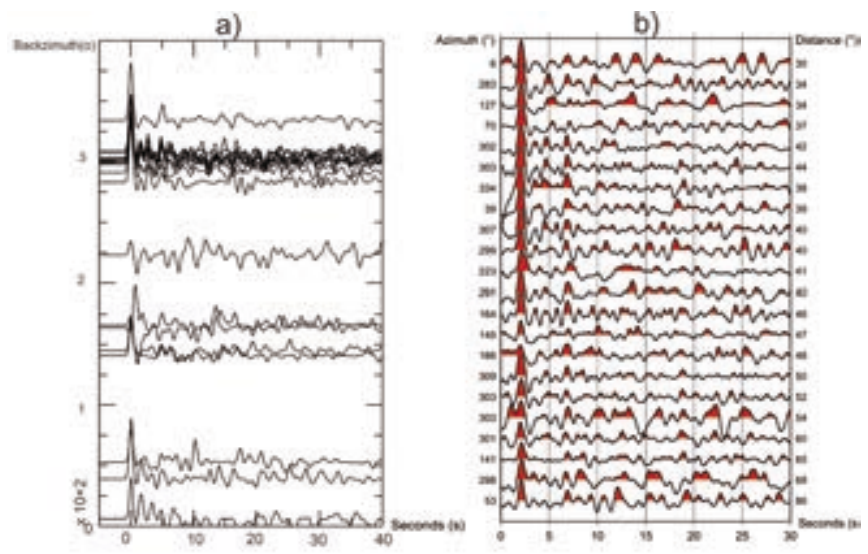

Fig. 4 - Resultado da FR para a estação BRA7 de acordo com a distribuição azimutal: a) Domínio do tempo; b) Domínio da frequência.

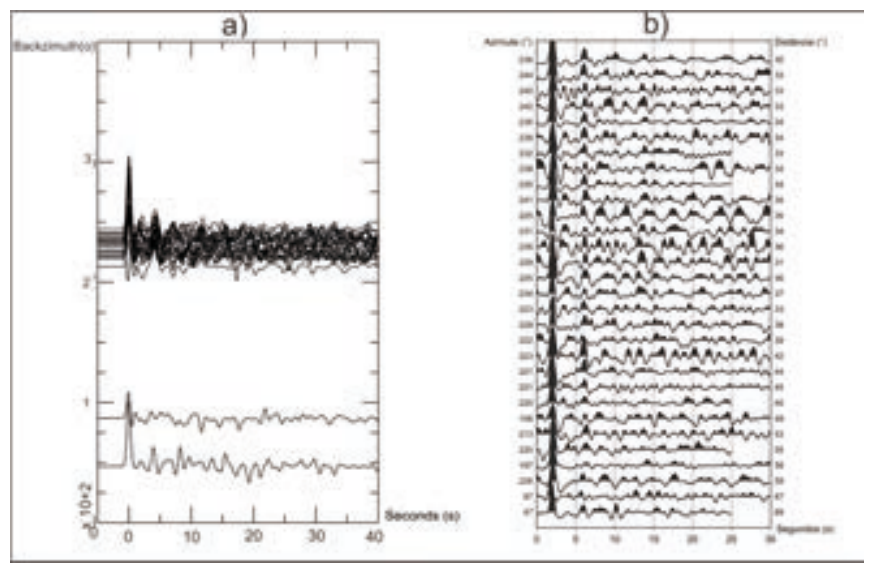

Fig. 5 - Resultado da FR para a estação FOR1 de acordo com a distribuição azimutal: a) Domínio do tempo; b) Domínio da frequência. 
No domínio do tempo, as Figs. 6 (a) e 7 (a) mostram as estimativas para a espessura crustal e a razão Vp/Vs obtidas pelo programa PWSS para as estaçóes BRA7 e FOR1, respectivamente. Os valores para as demais estaçôes não apresentaram fases Ps e múltiplas coerentes. Entretanto, mesmo com erros relativamente altos, estimamos a espessura da crosta e a razão $\mathrm{Vp} / \mathrm{Vs}$ para que sirvam, pelo menos, como dados preliminares, sendo necessário a vinculação com os resultados obtidos no domínio da frequência.

No domínio da frequência, para todas as estaçôes foram obtidas as espessuras crustais e razão $\mathrm{Vp} / \mathrm{Vs}$. Dois dos resultados onde as fases Ps e múltiplas foram mais claras são visualizados nas estaçóes BRA7 e FOR1, mostrados nas figuras 6 (b) e 7 (b).


Fig. 6 - a) Resultado do PWSS para a estação BRA7. Os retângulos vermelhos indicam a onda Ps e as reflexôes múltiplas (Ppps e Psps+Ppss); b) Resultado do HK-Stacking para a estaçáo BRA7.

A elipse vermelha indica a variação nos valores da espessura crustal e da razáo $\mathrm{Vp} / \mathrm{Vs}$.
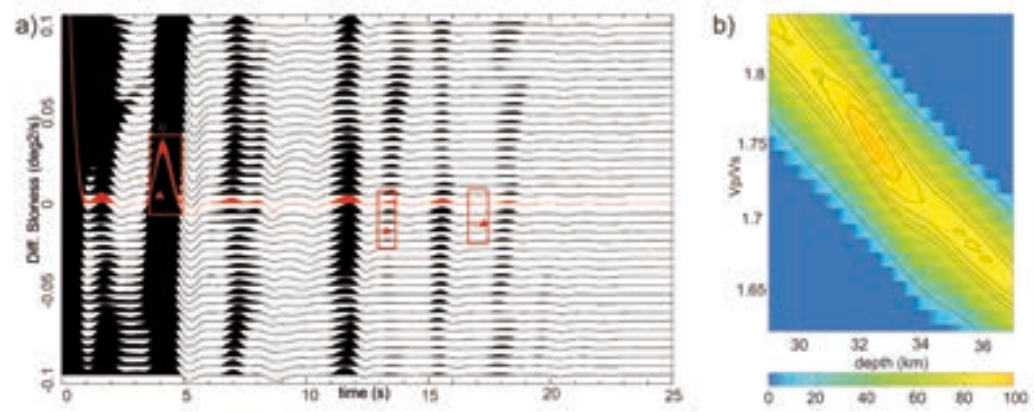

Fig. 7 - a) Resultado do PWSS para a estação FOR1. Os retângulos vermelhos indicam a onda Ps e as reflexốes múltiplas (Ppps e Psps+Ppss); b) Resultado do HK-Stacking para a estação FOR1.

A elipse vermelha indica a variação nos valores da espessura crustal e da razão $\mathrm{Vp} / \mathrm{Vs}$.

\section{4 - Conclusão}

O estudo apresenta as estimativas de espessura crustal e de razão $\mathrm{Vp} / \mathrm{Vs}$ por meio da Função do Receptor nos domínios do tempo e da frequência, sendo os programas PWSS 
e HK-Stacking usados para o empilhamento inclinado ponderado pela fase. Nas estaçóes BRA7 e FOR1 o empilhamento produzido pelo PWSS mostrou as fases Ps e as reflexóes múltiplas evidentes. Já nas estaçôes CAN3, JAN7, PDRB, SFA e TUCA, o PWSS não obteve essas fases de maneira clara. Embora a maioria das estaçóes não apresente um empilhamento de fases claro, foram calculadas as estimativas da espessura da crosta e a $\mathrm{Vp} / \mathrm{Vs}$. Para isso, houve necessidade de relacionar esses dados com os valores obtidos no domínio do tempo para as mesmas estaçóes sismográficas (ALBUQUERQUE et al., 2010) ou na mesma província geológica (BIANCHI, 2008).

Já os resultados obtidos no domínio da freqüência foram mais abrangentes, pois foi possível fazer o empilhamento para todas as estaçóes sismográficas.

Vale salientar que os valores encontrados sáo conectados diretamente com alguns fatores, os quais podem afetar a interpretação dos dados, sendo esses: a baixa razão sinal ruído, a baixa quantidade de telessimos no registro de algumas estaçóes, a possível má calibração do sismômetro ou a concentração de sismos em um mesmo azimute. Esse último fator é de fácil observação na própria FR (figuras 4 (a) e 5 (b)), onde se nota uma maior concentração de sismos provenientes da região andina (região limítrofe de placas tectônicas e regiáo sismologicamente ativa). Para amenizar esses problemas seria necessário um maior período de captação de dados.

A pesquisa mostrou que a Função do Receptor nos domínios do tempo e da frequência pode ser usada como uma ferramenta importante na definiçáo da espessura crustal, pois quando utilizadas conjuntamente, torna-se possível aumentar a acurácia, em que cada método pode corroborar os resultados do outro, ou até mesmo levantar questionamentos sobre as espessuras crustais anteriormente calculadas.

\section{Referências Bibliográficas}

Albuquerque, D. F., PAVÃO, C. G., FRANÇA, G. S. \& SILVA, P. G. N. (2010) - O Estudo da espessura crustal e razâo Vp/Vs para as estaçōes da Rede Sismográfica Nacional (RSN-SIS-UnB). IV Simpósio Brasileiro de Geofísica.

AMMON, C. J. (1991) - The isolation effects from teleseismic P-waveforms. Bull. Seism. Soc. Am. 81, p. $2504-251$.

AMMON, C. J. (1997) - An overview of Receiver-Function Analysis. Disponível em: < http://eqseis.geosc. psu.edu/ cammon/HTML/RftnDocs/rftn01.html >. (Consultado em 2012.03.26).

AMMOM, C. J., G. E. RANDALL \& G. ZANDT (1990) - On the nonuniqueness of receiver functions inversions, J. Geophys. Res., 95, p. 15303-15318.

BIANCHI, M. (2008) - Variação da estrutura da crosta, litosfera e manto para a plataforma Sul Americana através de funçôes do receptor para ondas P e S. Tese de Doutorado, Instituto de Astronomia, Geofísica e Ciências Atmosféricas-USP (São Paulo, Brasil), 133 p.

FRANÇA, G. S. L. (2003) - Estrutura da crosta no Sudeste e Centro-Oeste do Brasil usando a Função do Receptor. Tese de Doutorado, Instituto de Astronomia, Geofísica e Ciências Atmosféricas-USP (Sáo Paulo, Brasil), 143 p.

GOLDSTEIN, P. \& SNOKE A. (2005) - SAC Availability for the IRIS Community, Incorporated Research Institutions For Seismology, Data Management Center, Eletronic Newsletter.

LANGSTON, C. A. (1979) - Structure under Mount Rainier, Washington, inferred from teleseismic body waves. J. Geophys. Res. 85, p. 4749-4762. 
LIGORRIA, J. P. \& AMMON, C. J. (1999) - Iterative deconvolution and receiver function estimation. Bulletin of the Seismological Society of America 89, p. 1395-1400.

OWENS, T. J., ZANDT, G., \& TAYLOR, S. R. (1984). Seismic evidence for an ancient rift beneath the Cumberland Plateau, Tennessee: a detailed analysis of broadband teleseismic P waveforms. Journal of Geophysical Research, 89, p. 7783-7795.

ZHU, L. \& KANAMORI, H. (2000) - Moho depth variation in southern California from teleseismic receiver functions. Journal of Geophysical Research, 105, p. 2696-2980. 